\title{
Changing Trends in Meteorological Elements and Reference Evapotranspiration in a Mega City: A Case Study in Shenzhen City, China
}

\author{
Haijun Liu, Xian Zhang, Liwei Zhang, and Xuming Wang \\ College of Water Sciences, Beijing Normal University, Beijing 100875, China \\ Correspondence should be addressed to Haijun Liu; shanxilhj@bnu.edu.cn
}

Received 26 September 2014; Revised 3 January 2015; Accepted 5 January 2015

Academic Editor: Andreas Matzarakis

Copyright @ 2015 Haijun Liu et al. This is an open access article distributed under the Creative Commons Attribution License, which permits unrestricted use, distribution, and reproduction in any medium, provided the original work is properly cited.

Shenzhen city was a farmland region before 1978, and it then developed to a mega city in China. This type of change in city can greatly affect the climatic conditions. In this study, the daily, monthly, and annual climatic variables and the reference crop evapotranspiration $\left(\mathrm{ET}_{0}\right)$ for Shenzhen from 1954 to 2012 were computed using the FAO Penman-Monteith equation (PM), and these parameters were analyzed to study the temporal trends of $\mathrm{ET}_{0}$ and meteorological factors. The trends and the time points of abrupt changes of $\mathrm{ET}_{0}$ and meteorological factors were tested using Mann-Kendall methods. Results show that, in the past 59 years, the annual $\mathrm{ET}_{0}$ first decreased from 1954 to 1978, then increased from 1979 to 1990, and now varied slightly after 1990. The mean air temperature rose gradually, and the relative humidity decreased as a whole. These trends finally resulted in an increasing trend in vapor pressure deficit (VPD). The wind speed showed a slightly decreasing trend. Both the annual total sunshine duration and net radiation showed trends of rapid decline. $\mathrm{ET}_{0}$ change is sensitive to the hours of sunshine and VPD. The significant increase in $\mathrm{ET}_{0}$ after 1979 was mainly due to the increased air temperature and decreased relative humidity.

\section{Introduction}

It has been confirmed that there has been a change in the global climate that is closely related to increases in the concentrations of atmospheric greenhouse gases $\left(\mathrm{CO}_{2}, \mathrm{NO}_{x}\right)[1]$. These changes in climate are expected to cause major changes in various climatic variables, such as precipitation, air temperature, relative humidity, and solar radiation [2]. According to the IPCC report [1], the air temperature at the earth's surface level increased by $0.74^{\circ} \mathrm{C}$ from 1906 to 2005 , and this rising trend of the air temperature is likely to continue in the 21st century, which will cause changes in the hydrological cycle by affecting precipitation and evaporation $[3,4]$. Bates et al. (2008) pointed out that, over the last century, precipitation has primarily increased over land in high northern latitudes but decreased from $10^{\circ} \mathrm{S}$ to $30^{\circ} \mathrm{N}$ since the 1970 s and globally the area of land classified as very dry has more than doubled since the 1970s due to climate change [4].
The trends for changes in the city climate may differ from those for farmland and forest regions because of changes in the energy balance caused by the surface albedo and components of air. In cities, the ground surface is primarily covered by concrete and asphalt, and the green ground surface and water surface only account for a small portion of the total area. For example, it has been reported that the percentage of green ground surface and water surface of the total city area is approximately $20.7 \%$ for Beijing City (2012), 38.3\% for Shanghai City (2012), and $42.6 \%$ for Tianjin City (2012). Due to the high albedo rate and low heat capacity of concrete and asphalt compared to those of green surfaces and water bodies, the air temperature is recorded as much higher in a city than in farmland $[1,4-7]$. The climate is also dryer in cities than in farmland due to the lower amount of water vapor caused by smaller evaporative surface prevailing in cities $[1,4,5]$.

The composition of the air may also change the energy balance in cities. With city development, a larger number of 


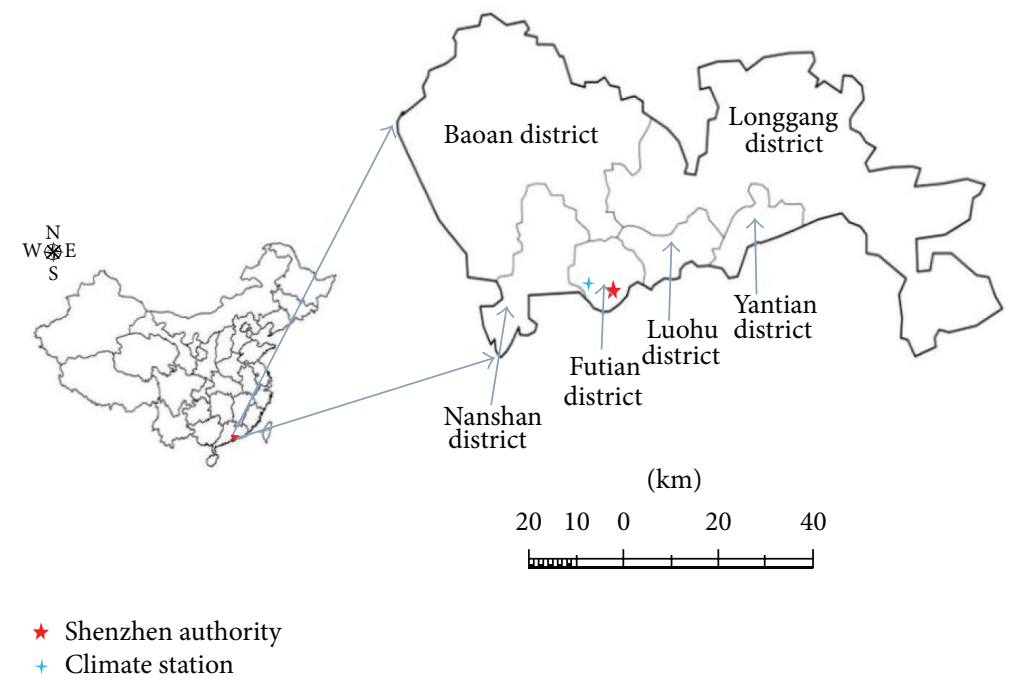

FIGURE 1: Schematic diagram of the research region (Shenzhen) and the meteorological station.

particles and particles with more complicated compositions are emitted into the air. In Beijing City, it has been reported that vehicular emissions of $\mathrm{HC}, \mathrm{CO}$, and $\mathrm{NO}_{x}$ were estimated to reach $13.33 \times 10^{4}, 100.02 \times 10^{4}$, and $7.55 \times 10^{4}$ tons, respectively, in 2005 [8], and vehicle emissions in the urban area made up $75 \%$ of the total emissions in Beijing in 2002 for vehicle-related pollutants [9]. In recent years, the "gray sky" phenomenon caused by fine particles (particles less than $2.5 \mu \mathrm{m}$ in aerodynamic diameter, or $\mathrm{PM}_{2.5}$ ) is an increasing public concern, caused by fossil fuels that play a decisive role in the development of economic and urban growth in the current period in China. In Shanghai, for example, the annual average $\mathrm{PM}_{2.5}$ concentrations in 2005 reached $56 \mu \mathrm{g} / \mathrm{m}^{3}$, which was much higher than the value proposed by the World Health Organization Air Quality Guidelines (WHO AQG) [10]. This phenomenon was also found in certain other areas abroad. Aziz and Bajwa (2008) showed that the major source of urban air pollution is the growing motor vehicular emission [11]. They pointed out that motor vehicular emission is a mixture of five key pollutants, namely, carbon monoxide (CO), hydrocarbons ( $\mathrm{HC})$, particulate matter $\left(\mathrm{PM}_{10}\right)$, nitrogen oxides $\left(\mathrm{NO}_{x}\right)$, and ozone $\left(\mathrm{O}_{3}\right)$.

Shenzhen city constitutes a special place in Chinese history. Before 1978, it was a small town, occupied by farmland and fishing areas, with a population of approximately 314,000 permanent residents. After that year, it was chosen as the first Special Economic Zone in China, after which the city developed quickly; nowadays it is one of the four largest cities in China. By the end of 2012, the city had a population of 10.55 million permanent residents, approximately 35 times the number compared with 1978 and it had a gross domestic product (GDP) of 20937 million dollars, approximately 6600 times higher than that in 1978. From 1979 to 2012, the farmland area decreased from 63553 to 8520 ha, whereas the construction area increased from 29 to 5260 ha.

We suppose that the urban development of Shenzhen may have altered the heat balance of the ground surface, thereby influencing climatic variables as well as the reference evapotranspiration changes.

\section{Data and Methods}

2.1. Site. Shenzhen city $\left(22^{\circ} 27^{\prime}-22^{\circ} 52^{\prime} \mathrm{N}, 113^{\circ} 46^{\prime}-114^{\circ} 47^{\prime} \mathrm{E}\right)$ lies in the southern region of Guangdong province in southeastern China (Figure 1). The area administered by the Shenzhen municipal government is $2,020 \mathrm{~km}^{2}$. Shenzhen has a typical subtropical maritime climate with plenty of rain, a mild climate, and numerous sunshine hours. The yearly mean precipitation is $1914 \mathrm{~mm}$ and the rainy season can range between April and September. The minimum precipitation is $912 \mathrm{~mm}$ (1962) and the maximum is $2747 \mathrm{~mm}$ (2001). The annual mean air temperature is $22.3^{\circ} \mathrm{C}$, with a minimum daily air temperature of $0.2^{\circ} \mathrm{C}$ (February 11,1957$)$ and a maximum of $38.7^{\circ} \mathrm{C}$ (July 10,1980 ). The mean yearly total sunshine hours are 2120 hours.

2.2. Meteorological Data. All meteorological data were collected from a national climatic station $\left(22^{\circ} 33^{\prime} \mathrm{N}, 114^{\circ} 06^{\prime} \mathrm{E}\right.$, $182 \mathrm{~m}$ above surface level) (Figure 1). The meteorological data include the atmospheric pressure, daily values of the precipitation, the mean, maximum, and minimum air temperatures, mean relative humidity, mean wind speed, and sunshine hours from 1954 to 2012.

\subsection{Methods}

2.3.1. Reference Crop Evapotranspiration. The reference crop evapotranspiration $\left(\mathrm{ET}_{0}\right)$ was calculated using the FAO Penman-Monteith method (hereafter denoted as PM). The PM method is [12]

$$
\mathrm{ET}_{0}=\frac{0.408 \Delta\left(R_{n}-G\right)+\gamma(900 /(T+273)) U_{2}\left(e_{s}-e_{a}\right)}{\Delta+\gamma\left(1+0.34 U_{2}\right)},
$$


where $\mathrm{ET}_{0}$ is the reference crop evapotranspiration, $\mathrm{mm} \cdot \mathrm{day}^{-1} ; R_{n}$ is the net radiation, $\mathrm{MJ} \cdot \mathrm{m}^{-2} \cdot \mathrm{day}^{-1} ; G$ is the soil heat flux that can be neglected at daily intervals [12], $\mathrm{MJ} \cdot \mathrm{m}^{-2} \cdot$ day $^{-1} ; \gamma$ is the psychrometric constant, $\mathrm{kPa} \cdot{ }^{\circ} \mathrm{C}^{-1} ; U_{2}$ is the wind speed measured at $2 \mathrm{~m}$ above ground surface, $\mathrm{m} \cdot \mathrm{s}^{-1} ; e_{s}$ and $e_{a}$ are the saturation and the actual vapor pressure, $\mathrm{kPa}$; and $\Delta$ is the slope of the saturation vapor pressure curve at the air temperature, $\mathrm{kPa} \cdot{ }^{\circ} \mathrm{C}^{-1}$. The monthly or yearly total $\mathrm{ET}_{0 \mathrm{~s}}$ is the sum of daily $\mathrm{ET}_{0}$ in an entire month or year.

The net radiation was not directly measured at Shenzhen station. Therefore, the net radiation was calculated using data for the daily sunshine hours and the maximum and minimum air temperatures, following the method suggested by Allen et al. (1998) [12].

The actual daily vapor pressure $\left(e_{a}\right)$ and vapor pressure deficit (VPD) were based on the daily mean air temperature and relative humidity and were calculated in the following way:

$$
\begin{gathered}
e_{a}=\mathrm{RH} \times e^{o}\left(T_{\text {mean }}\right), \\
\mathrm{VPD}=(1-\mathrm{RH}) \times e^{o}\left(T_{\text {mean }}\right),
\end{gathered}
$$

where $\mathrm{RH}$ is daily mean relative humidity, $\%$; $T_{\text {mean }}$ is the daily mean temperature, ${ }^{\circ} \mathrm{C}$; and $e^{o}\left(T_{\text {mean }}\right)$ is saturated vapor pressure at $T_{\text {mean }}, \mathrm{kPa} \cdot e^{o}\left(T_{\text {mean }}\right)$ is calculated as follows:

$$
e^{o}\left(T_{\text {mean }}\right)=0.6108 \exp \left(\frac{17.27 T_{\text {mean }}}{T_{\text {mean }}+237.3}\right) .
$$

2.3.2. Mann-Kendall Test. The Mann-Kendall test is one of the most widely used nonparametric tests to detect significant trends in climatic variables and potential evapotranspiration in time series [13-15].

Mann-Kendall Test for Temporal-Trend Analysis. The MannKendall test is based on the statistic $S$ [16]:

$$
S=\sum_{i=1}^{N-1} \sum_{j=i+1}^{N} \operatorname{sign}\left(x_{j}-x_{i}\right)
$$

where $x_{i}$ and $x_{j}$ are two generic sequential data values of the variable, $N$ is the length of the data set, and the sign $(X)$ takes the following values:

$$
\operatorname{sign}(X)= \begin{cases}+1 & \text { if } X>0 \\ 0, & \text { if } X=0 \\ -1 & \text { if } X<0\end{cases}
$$

A positive $S$ in (4) represents a positive trend in the observed data series, and vice versa. Under the null hypothesis of no trend in the data, $H_{0}$, the statistic $S$ is approximately normally distributed with the mean $E(S)=0$. For data sets with more than ten values, the variance associated with the
Mann-Kendall statistic $S(\operatorname{VAR}(S))$ can be calculated after considering the distribution as very close to normal:

$$
\begin{aligned}
\operatorname{VAR}(S)=\frac{1}{18}[ & N(N-1)(2 N+5) \\
& \left.\quad-\sum_{p=1}^{q} t_{p}\left(t_{p}-1\right)\left(2 t_{p}+5\right)\right],
\end{aligned}
$$

where $q$ is the number of tied groups and $t_{p}$ is the number of data values in the $p$ th group.

The values of $S$ and $\operatorname{VAR}(S)$ are used to compute the test statistic $Z$ as follows:

$$
Z= \begin{cases}\frac{S-1}{\sqrt{\operatorname{VAR}(S)}} & \text { if } S>0 \\ 0, & \text { if } S=0 \\ \frac{S+1}{\sqrt{\operatorname{VAR}(S)}} & \text { if } S<0 .\end{cases}
$$

The presence of a statistically significant trend is evaluated using the $Z$ value. A positive (negative) value of $Z$ indicates an upward (downward) trend. The statistic $Z$ has a normal distribution. To test for either an upward or downward monotonic trend (a two-tailed test) at the $\alpha$ level of significance, $H_{0}$ is rejected if the absolute value of $Z$ is greater than $Z_{1-\alpha / 2}$, where $Z_{1-\alpha / 2}$ is obtained from the standard normal cumulative distribution tables. The tested significance level, $\alpha$, was set to 0.01 in this study.

Mann-Kendall Test for Mutation Point Analysis. We suppose that a time series $\left(x_{1}, x_{2}, \ldots, x_{n}\right)$ exists. One order series, $m_{i}$, is constructed to represent the sample accumulative number of $x_{i}>x_{j}(1 \leq j \leq i) . d_{k}$ is defined in the following way:

$$
d_{k}=\sum_{1}^{k} m_{i} \quad(2 \leq k \leq n) .
$$

The mean value and variance of $d_{k}$ can be approximately expressed as follows:

$$
\begin{gathered}
E\left(d_{k}\right)=\frac{k(k-1)}{4}, \\
\operatorname{var}\left(d_{k}\right)=\frac{n(n-1)(2 n+5)}{72}, \quad(2 \leq k \leq n) .
\end{gathered}
$$

Under the hypothesis that the time series is random and independent, the statistic is defined in the following way:

$$
\mathrm{UF}_{k}=\frac{d_{k}-E\left(d_{k}\right)}{\operatorname{var}\left(d_{k}\right)} \quad(k=1,2, \ldots, n) .
$$

Given the significance level of $\alpha,\left|\mathrm{UF}_{k}\right|>\mathrm{UF}_{\alpha / 2}$ means that the series has an obvious change trend. Time series $x_{i}$ is arranged in reverse order and is calculated with (9), while ensuring that

$$
\begin{aligned}
& \mathrm{UB}_{k}=-\mathrm{UF}_{k} \\
& k=n+1-k .
\end{aligned}
$$


By analyzing the statistical series $\mathrm{UF}_{k}$ and $\mathrm{UB}_{k}$, the change trend of series $x_{i}$ can be further analyzed, and the mutation time and region can be determined. $\mathrm{UF}_{k}>0$ indicates that the series tends to increase, and $\mathrm{UF}_{k}<0$ indicates that the series tends to decrease. When the series exceed the credibility line, they exhibit an obvious increasing or decreasing trend. If an intersection point exists between the curves of $\mathrm{UF}_{k}$ and $\mathrm{UB}_{k}$ and falls between the credibility lines, the corresponding time of the intersection point is the starting moment of mutation.

In this study, the statistical analysis software DPS (version DPS 14.5, developed by Zhejiang University, China) was used to analyze the mutation point of the temporal trends of $\mathrm{ET}_{0}$ and the meteorological variables [17]. The credibility line is drawn at the significance level of $\alpha=0.01$.

2.3.3. Sensitivity-Analysis Method. Sensitivity analysis was employed to identify the climatic variables that most strongly influence $\mathrm{ET}_{0}$ following the method proposed by Möller et al. (2004) and Liu et al. (2014) $[15,18]$. In this study, the temporal trends of most climatic variables showed abrupt change in 1978, and the climatic variables during 1954-1978 were significantly $(P<0.01)$ higher or lower than those during 19922012; see Sections 3.1.1 to 3.1.6 in the following text. Hence, data during these two periods were used to assess the climate change impact on $\mathrm{ET}_{0}$. The detailed processes of the sensitivity analysis are described as follows: (1) the mean values of the air temperature, relative humidity, wind speed, and sunshine hours in each day of a year were calculated using climatic data from 1954 to 1978, and the corresponding daily and annual $\mathrm{ET}_{0}$ were calculated using these mean daily values and the Penman-Monteith method. The mean daily value for each climatic variable was set as the reference climatic variable, and the calculated $\mathrm{ET}_{0}$ was set as the reference $\mathrm{ET}_{0}$. (2) The sensitivity of each climatic variable to $\mathrm{ET}_{0}$ was analyzed by comparing the reference $\mathrm{ET}_{0}$ and the $\mathrm{ET}_{0}$ calculated by changing one variable with a rate of $-15,-10,-5,5,10$, and $15 \%$ and keeping the other variables identical to the reference climatic variables. Then, a figure was drawn based on these data (Figure 10). (3) The mean values of the air temperature, relative humidity, wind speed, and sunshine hours in each day of a year were calculated using climatic data from 1992 to 2012. The corresponding $\mathrm{ET}_{0}$ was calculated by setting one climatic variable as those during 1992 and 2012 and the others as the reference climatic variable (in step (1)) and then calculating $\mathrm{ET}_{0}$ and comparing it with the reference $\mathrm{ET}_{0}$. The relative change in $\mathrm{ET}_{0}$ caused by each climatic change during 1992 to 2012 is marked in Figure 10. The most sensitive variable to a change in $\mathrm{ET}_{0}$ is determined by comparing the relative $\mathrm{ET}_{0}$ changes caused by each variable.

\section{Results}

\subsection{Annual Distributions and Trends in the Changes of Climatic Variables}

3.1.1. Sunshine Hours and Solar Radiation. The annual sunshine duration and annual total radiation during the period

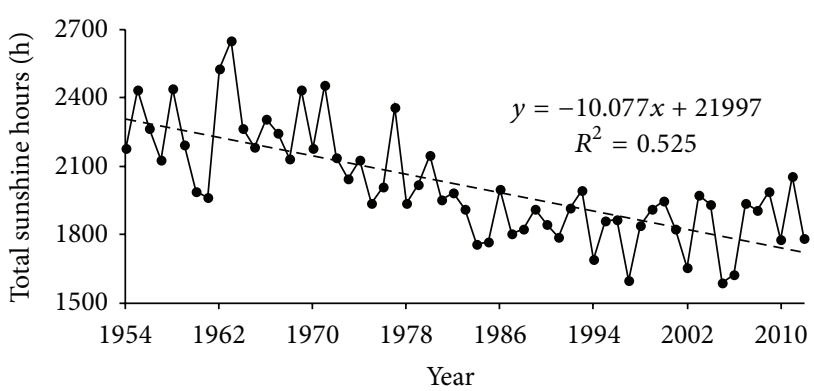

(a)

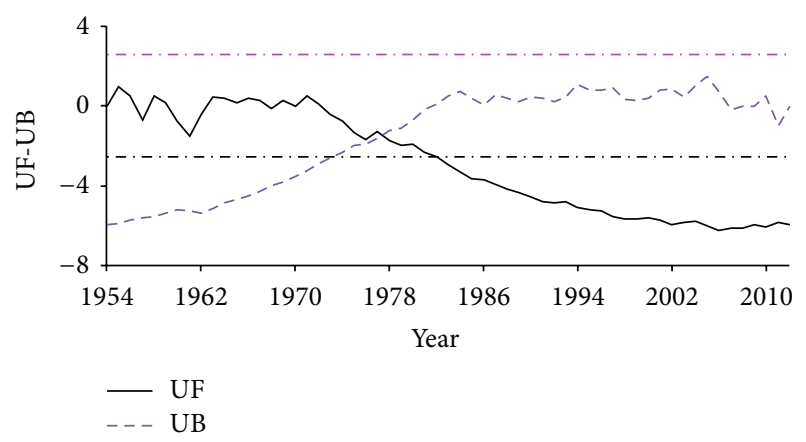

(b)

Figure 2: Temporal change in the yearly sunshine duration (a) and the trend results from the Mann-Kendall method (b).

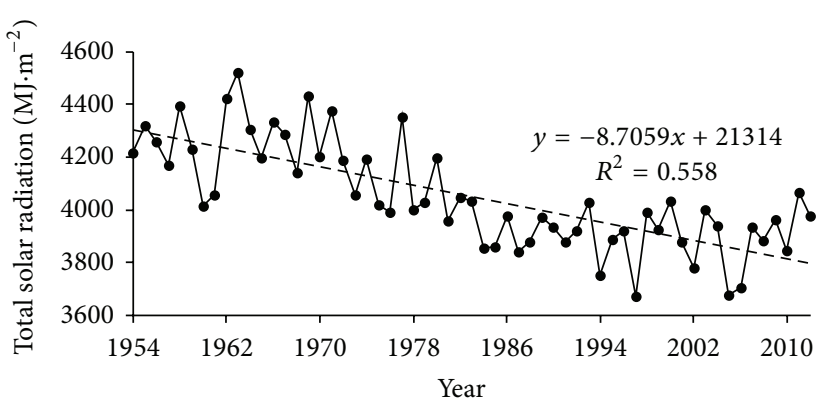

(a)

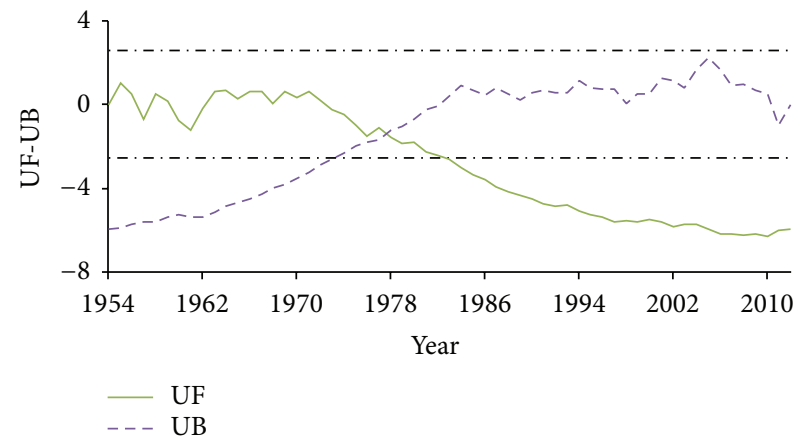

(b)

FIGURE 3: Temporal trend in the yearly total solar radiation (a) and the trend results from the Mann-Kendall method (b).

from 1954 to 2012 are given in Figures 2 and 3. It can be seen in Figure 2 that the annual sunshine duration showed 


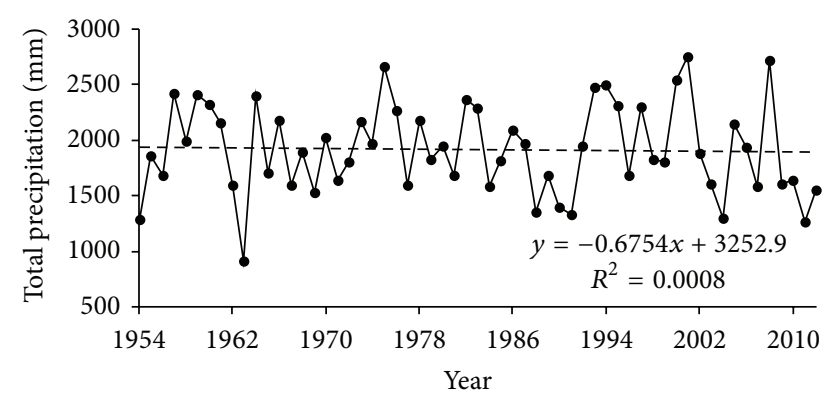

(a)

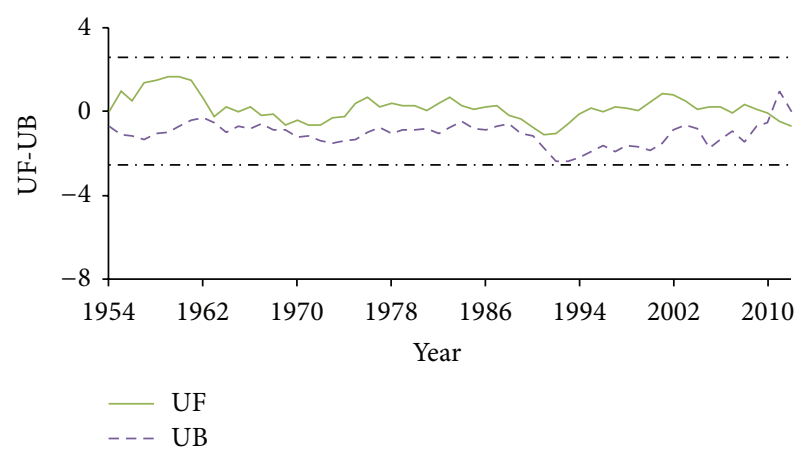

(b)

FIGURE 4: Temporal trend of the yearly total precipitation (a) and the trend results from the Mann-Kendall method (b).

an obvious decline, which decreased from 2651 to 1590 hours with an average of 2014 hours (Figure 2(a)). Through the twotailed test (UF and UB lines), we found that the decreasing trend of the sunshine hours is obvious for the period from 1982 to 2012, and the increasing trend is obvious for the period of 1954 to 1973. Similar to the trend for the sunshine duration, the solar radiation also showed an obvious declining trend, which ranges from 3672 to $4520 \mathrm{MJ} \cdot \mathrm{m}^{-2}$, with an average of $4050 \mathrm{MJ} \cdot \mathrm{m}^{-2}$ (Figure 3(a)). The two-tailed test showed that the solar radiation values from 1982 to 2012 were significantly lower than those from 1954 to 1973 . The shifting mutation points of the sunshine duration and the solar radiation are all found in 1978 using the Mann-Kendall mutational test $(P<0.01)$ (Figures 2 and 3(b)).

3.1.2. Precipitation. The annual total precipitation values during the period from 1954 to 2012 are given in Figure 4. It can be seen in Figure 4 that the highest precipitation value was $2747 \mathrm{~mm}$ in 2001 and the lowest was $912 \mathrm{~mm}$ in 1963 (Figure 4(a)). The annual mean was $1914 \mathrm{~mm}$ during the period from 1954 to 2012. The precipitation varied greatly over the years, whereas the trend test showed that the temporal trend of the annual precipitation is not significant, and a mutation point has not been tested (Figure 4(b)).

3.1.3. Relative Humidity. The daily mean relative humidity during the period from 1954 to 2012 is given in Figure 5. It can be seen that the daily mean relative humidity increased slightly in the first 20 years followed by an obvious decline

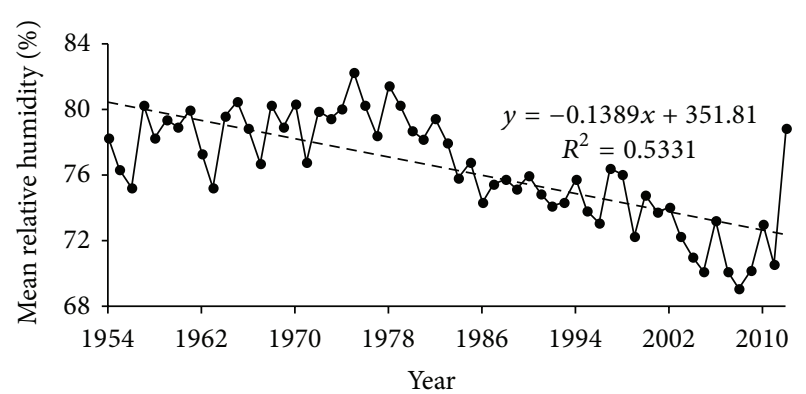

(a)

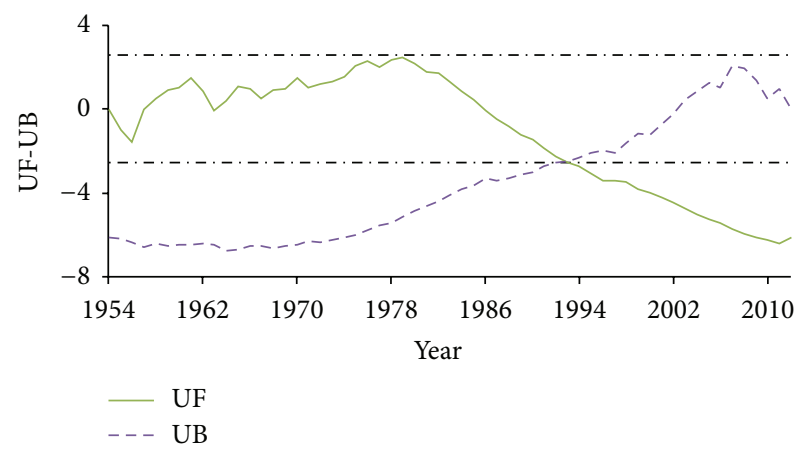

(b)

FIGURE 5: Temporal trend of the mean relative humidity (a) and the trend results from the Mann-Kendall method (b).

after 1978; the range is from $69.1 \%$ to $82.2 \%$, and the average is $76.4 \%$ (Figure 5(a)). From the Mann-Kendall test $(P<0.01)$, we found that the averaged relative humidity value during the period from 1992 to 2012 is significantly $(P<0.01)$ lower than the period from 1954 to 1992.

3.1.4. Air Temperature. The mean air temperature during the period from 1954 to 2012 is shown in Figure 6. According to Figure 6 the mean air temperature showed an obviously increasing trend, and the values range from 21.5 to $23.9^{\circ} \mathrm{C}$ with an average value of $22.6^{\circ} \mathrm{C}$ (Figure 6(a)). The statistical result showed that the mean air temperature over the period from 1990 to 2012 is significantly $(P<0.01)$ higher than those over the period from 1954 to 1983 (Figure 6(b)).

3.1.5. Vapor Pressure Deficit. Figure 7(a) shows the temporal trend of the vapor pressure deficit (VPD) during the period from 1954 to 2012 . VPD ranges from 0.449 to $0.867 \mathrm{kPa}$, and the average is $0.648 \mathrm{kPa}$. There is no significant temporal trend for VPD from 1954 to 1977, and after 1978, VPD increased greatly. It was found that the average VPD during the period from 1992 to 2012 is significantly $(P<0.01)$ higher than the values from 1954 to 1991, according to the MannKendall mutational test.

3.1.6. Wind Speed. The annual mean wind speed varied greatly during the period from 1954 to 2012 (Figure 8(a)). Clearly, decreasing trends were found from 1954 to 1977 and from 1987 to 2012, whereas increasing trend was found from 


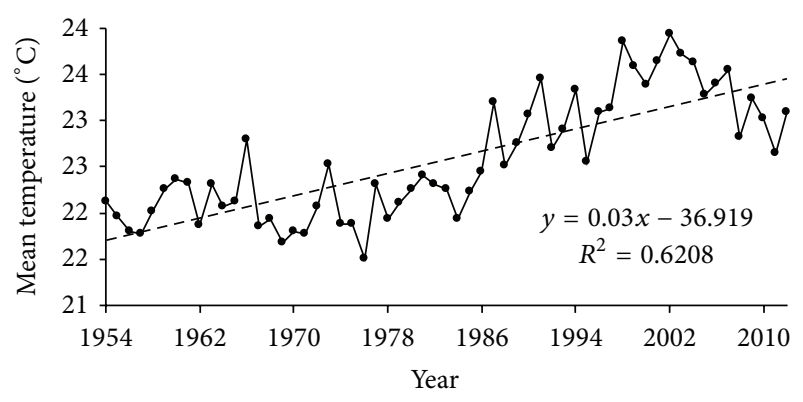

(a)

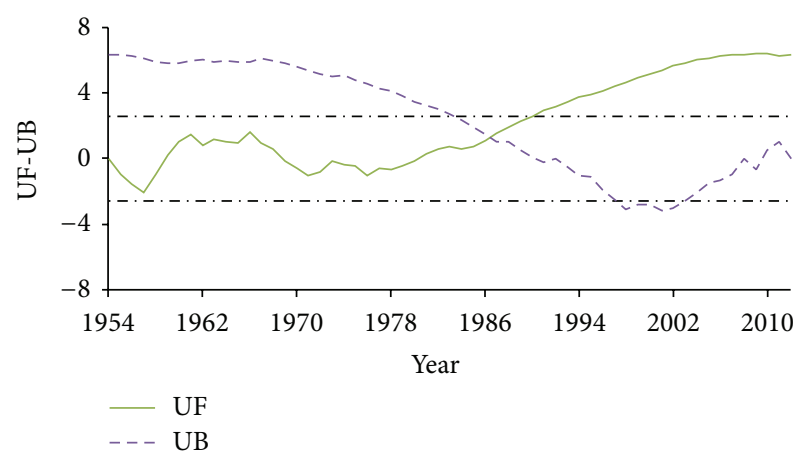

(b)

FIGURE 6: Temporal trend of the mean temperature (a) and the trend results from the Mann-Kendall method (b).

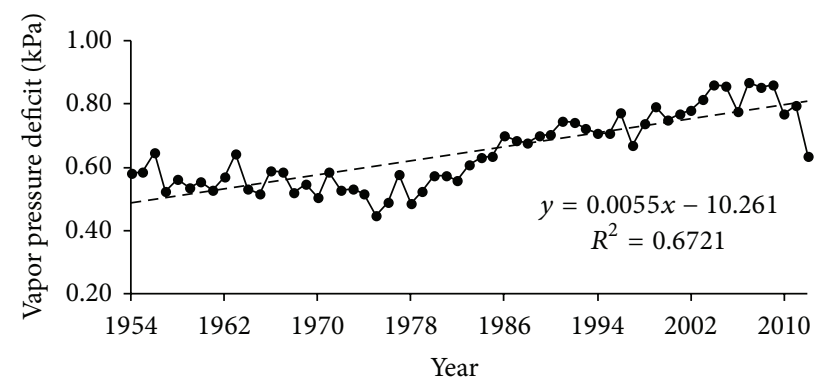

(a)

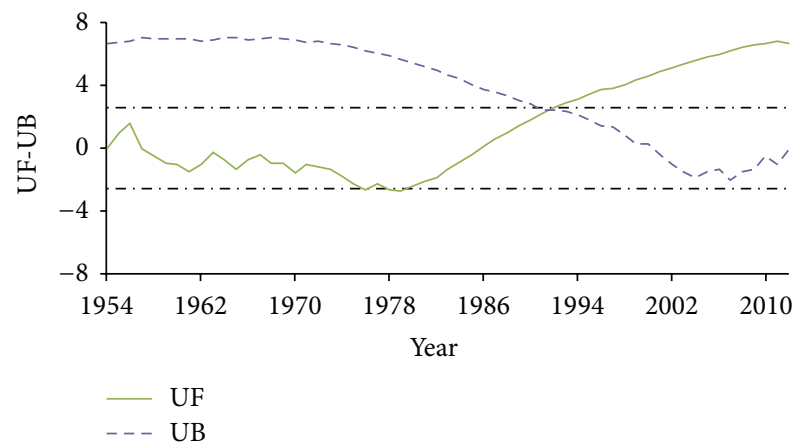

(b)

FIGURE 7: Temporal trend of the mean vapor pressure deficit (a) and the trend results from the Mann-Kendall method (b).

1978 to 1986. It can be seen in Figure 8(a) that the maximum wind speed was $3.72 \mathrm{~m} / \mathrm{s}$ in 1954, the minimum was $1.78 \mathrm{~m} / \mathrm{s}$

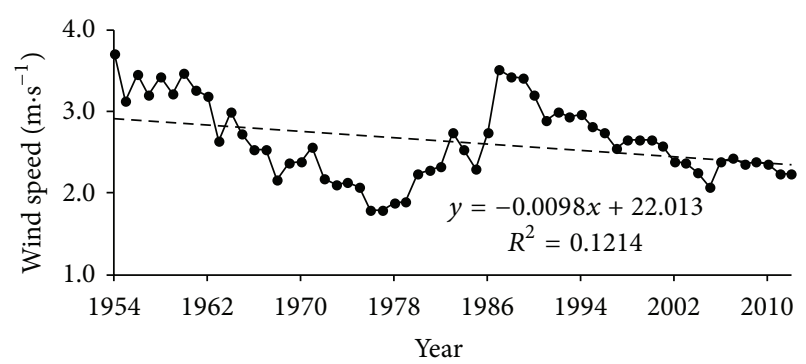

(a)

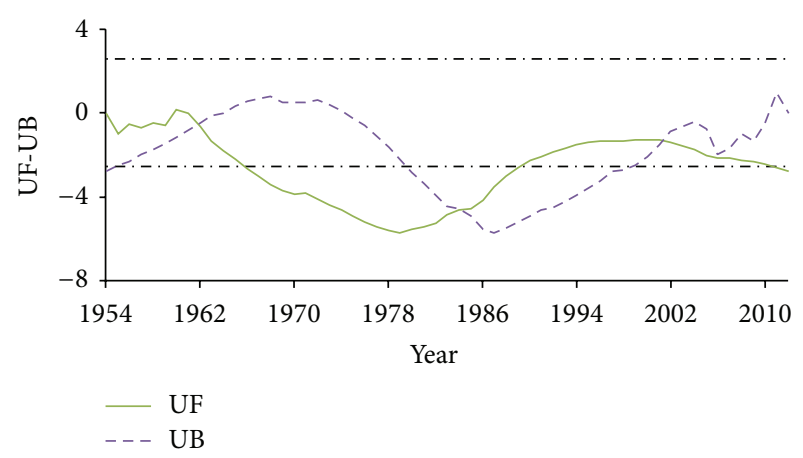

(b)

FIGURE 8: Temporal trend of the mean wind speed (a) and the trend results from the Mann-Kendall method (b).

in 1977 , and the annual mean was $2.60 \mathrm{~m} / \mathrm{s}$. The statistical results show that there were no significant temporal trends from 1954 to 2012.

3.2. Reference Evapotranspiration $\left(E T_{0}\right)$. The annual total $\mathrm{ET}_{0}$ varied from 946 to $1373 \mathrm{~mm}$ with a total mean of $1187 \mathrm{~mm}$. Figure 9(a) shows the change in the annual $\mathrm{ET}_{0}$ over the past 59 years. According to Figure 9(a) $\mathrm{ET}_{0}$ firstly decreased gradually from 1954 to 1978 , then increased from 1978 to 1992, and lastly varied slightly after 1992. From 1954 to 1978 the annual total $\mathrm{ET}_{0}$ decreased from 1285 to $946 \mathrm{~mm}$ with a mean value of $1110 \mathrm{~mm}$; afterwards, the annual total $\mathrm{ET}_{0}$ increased from 1118 to $1373 \mathrm{~mm}$ with a mean value of $1284 \mathrm{~mm}$ during the period from 1992 to 2012. The mean $\mathrm{ET}_{0}$ in the period of 1992-2012 increased by $15.6 \%$ over those in the period of 1954-1978, indicating a great increase in evaporation potential. The statistical results based on the Mann-Kendall test $(P<0.01)$ (Figure 9(b)) showed that $\mathrm{ET}_{0}$ during the period from 1972 to 1987 was significantly lower than that from 2001 to 2012, which was significantly higher than those in other periods. The shifting mutation point for $\mathrm{ET}_{0}$ is found at 1992 by the Mann-Kendall test (Figure 9(b)).

For analyzing the yearly $\mathrm{ET}_{0}$ distribution, the total $\mathrm{ET}_{0}$ for each month was calculated and the averaged month total $\mathrm{ET}_{0 \mathrm{~s}}$ in period of 1954-1978 and 1992-2012 were calculated, respectively. The monthly $\mathrm{ET}_{0}$ distributions in these two periods and in all study period (1954-2012) are showed in Figure 10. The highest monthly $\mathrm{ET}_{0}$ generally appears in July and August, and the lowest in January and February. Monthly ET $\mathrm{ET}_{0}$ from May to November are generally higher than $100 \mathrm{~mm}$, 
TABLE 1: Mean values of each climatic variable in the periods of 1954-1978 and 1992-2012 and changes of each climatic variable to ET 0 variation.

\begin{tabular}{|c|c|c|c|c|}
\hline & $\begin{array}{l}\text { Air temperature } \\
{ }^{\circ} \mathrm{C} \\
\end{array}$ & $\begin{array}{c}\text { Relative humidity } \\
\%\end{array}$ & $\begin{array}{c}\text { Sunshine hours } \\
\text { Hours/day }\end{array}$ & $\begin{array}{c}\text { Wind speed } \\
\mathrm{m} / \mathrm{s}\end{array}$ \\
\hline \multicolumn{5}{|l|}{ Mean values } \\
\hline 1954-1978 & 22.0 & 78.9 & 6.08 & 2.68 \\
\hline $1992-2012$ & 23.3 & 73.2 & 5.04 & 2.52 \\
\hline Climate change amount & -5.7 & 1.3 & -0.16 & -1.04 \\
\hline Climate change percentage (\%) & -7.2 & 5.9 & -6.0 & -17.1 \\
\hline $\mathrm{ET}_{0}$ change percentage caused by each climatic variable (\%) & 14.6 & 5.3 & -1.3 & -3.2 \\
\hline
\end{tabular}

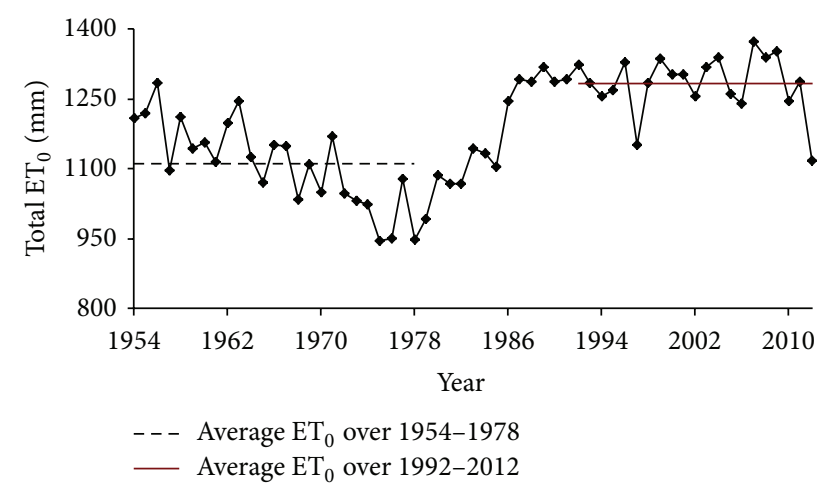

(a)

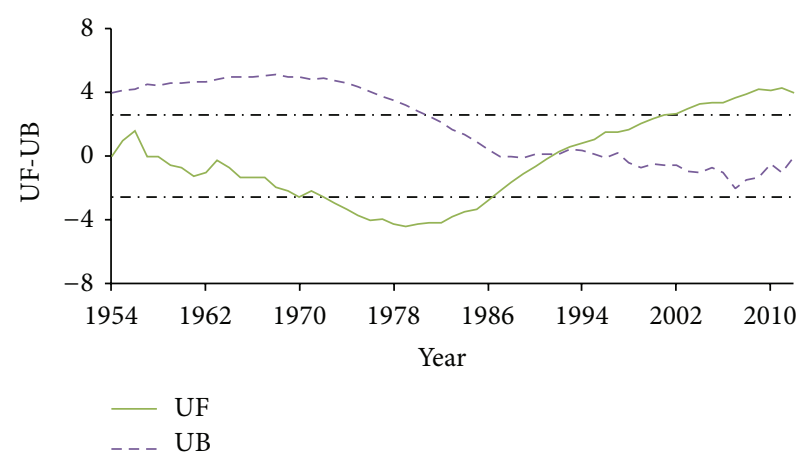

(b)

FIgure 9: Temporal trend of the yearly total $\mathrm{ET}_{0}$ (a) and the trend results from the Mann-Kendall method (b).

and the total $\mathrm{ET}_{0}$ in this period accounts for approximately $1 / 3$ the yearly total. Monthly $\mathrm{ET}_{0 \mathrm{~s}}$ in the period of $1992-2012$ are all higher by $5-30 \mathrm{~mm}$ or $7-25 \%$ than those in the $1954-$ 1978 period. The most increases in monthly $\mathrm{ET}_{0}$ are found in period from July to September, and the lowest from January to April with an increase of less than $7 \mathrm{~mm}$. Therefore, the great increase in $\mathrm{ET}_{0}$ in summer (generally from June to October) makes main contribution to yearly $\mathrm{ET}_{0}$.

3.3. Sensitivity Analysis of $E T_{0}$ to the Change of Climatic Variables. Figures 2 to 8 show that most mutation points for most of the climatic variables were found during the period from 1978 to 1992, and the mean values of the climatic variables over the period from 1954 to 1978 were significantly

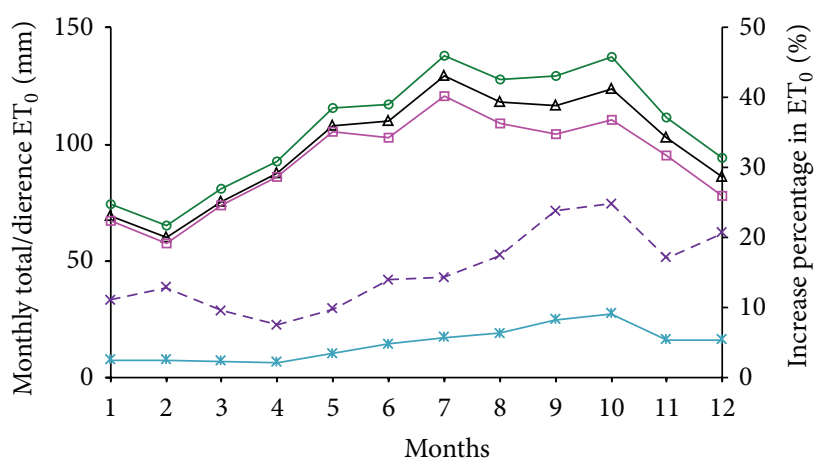

$$
\begin{aligned}
& \triangle \text { Monthly mean from period of } 1954-2012 \\
& \multimap-\text { Monthly mean from period of } 1992-2012 \\
& \square-\text { Monthly mean from period of } 1954-1978 \\
& \rightarrow-\text { Increase in } \mathrm{ET}_{0} \text { from } 1954-1978 \text { to } 1992-2012 \\
& -*-\text { Increase percentage in } \mathrm{ET}_{0}
\end{aligned}
$$

FIGURE 10: Yearly distribution of $\mathrm{ET}_{0}$ averaged in the periods of 1954-1978, 1992-2012, and 1954-2012. ET 0 increase amount and the corresponding increase percentage in each month from periods of 1954-1978 to 1992-2012 were showed.

$(P<0.01)$ higher/lower than those during the period from 1992 to 2012. Hence, the mean values of each variable during the two periods from 1954 to 1978 and from 1992 to 2012 were calculated and used to analyze their change effects on the $\mathrm{ET}_{0}$ changes, following the method described in Section 2.3.3. The summary of the mean values of each climate and their effects on $\mathrm{ET}_{0}$ were listed in Table 1 and Figure 11.

It can be seen in Table 1 that the daily mean relative humidity, daily mean air temperature, wind speed, and sunshine hours from the period of 1954-1978 to 1992-2012 were $-7.2,5.9,-6.0$, and $-17.1 \%$, respectively, which resulted in $\mathrm{ET}_{0}$ changes by $14.6,5.3,-1.3$, and $-3.2 \%$, respectively. The contribution of each climate variable's variation from 19541978 to $1992-2012$ to $\mathrm{ET}_{0}$ change is shown in Figure 11. It can be found that decrease in relative humidity accounted for approximately $60 \%$ variation in $\mathrm{ET}_{0}$, followed by temperature increase with a contribution of $22 \%$, and sunshine hours reduction of $13 \%$. Wind speed accounted for $6 \%$ variation in $\mathrm{ET}_{0}$. Similarly in another mega city, Beijing in China, the order of climate change to $\mathrm{ET}_{0}$ variation from main to weak is air temperature, relative humidity, sunshine hours, and wind speed [14]. 


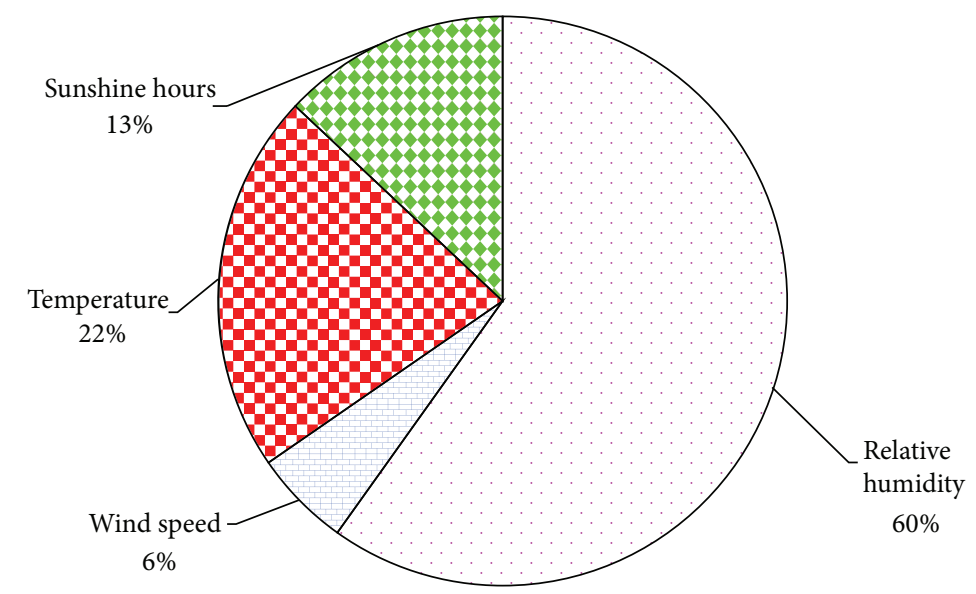

FIGURE 11: The contribution of each climatic variable change to $\mathrm{ET}_{0}$ variation.

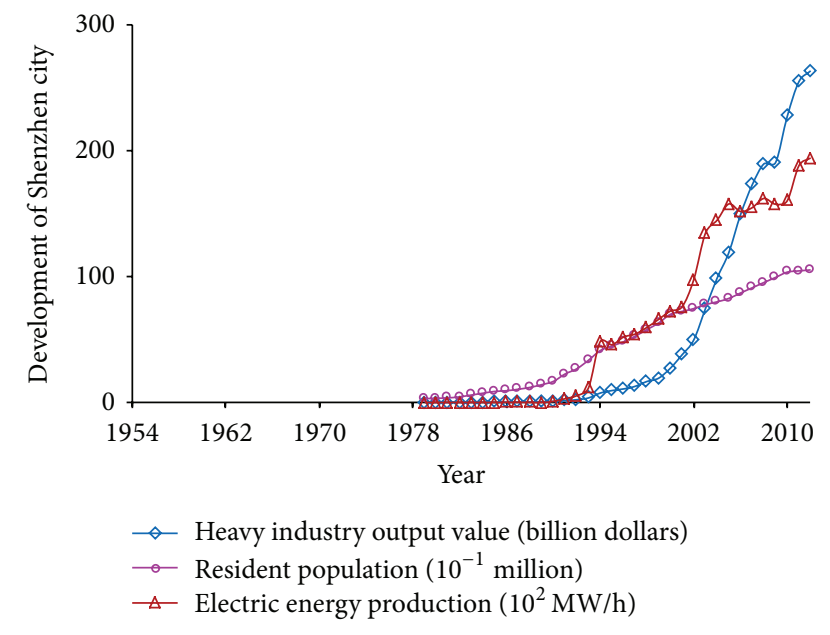

FIGURE 12: Temporal trend of the development of Shenzhen city.

\section{Discussion}

4.1. Change in the Sunshine Hours and Urban Development. Sunshine hours generally depend on the cloud cover, manmade aerosols, and certain air pollutants (including $\mathrm{SO}_{2}$, $\mathrm{NO}_{x}$, and $\left.\mathrm{PM}\right)[19,20]$. Recent studies indicated that the most probable cause for the depression of sunshine hours or solar radiation is in the increased concentrations of manmade aerosols and other air pollutants [1, 19-22]. In this study, the sunshine hours and amount of radiation showed clear decreasing trends after 1970, and they were significantly lower after 1980 during rapid urban development.

Figure 12 shows the increasing trends of the resident population, heavy industry output value, and electric energy production. It is confirmed that the increasing trend in the energy consumption corresponds to increased emission of polluted particles, including $\mathrm{CO}, \mathrm{CO}_{2}, \mathrm{NO}_{x}, \mathrm{SO}_{x}, \mathrm{PM}_{2.5}, \mathrm{O}_{3}$, and $\mathrm{HC}$. These particles may result in an increase in the atmospheric aerosol concentration [23-27], which can directly attenuate the surface solar radiation (SSR) by scattering and absorbing solar radiation (direct effect) or can indirectly attenuate SSR by their ability to act as cloud condensation nuclei, thereby increasing the cloud reflectivity and lifetime (first and second indirect effects) [24, 28]. A remarkable decline in SSR between the 1950s and the 1980s was found in several studies that were performed at selected observation stations based on sites in Europe, the Baltics, the South Pole, Germany, and the former Soviet Union [21]. Today, a comprehensive literature exists that confirms the declines of SSR during this period in many places around the world [29]. In Beijing and several other Chinese cities, the decline of sunshine hours and SSR has also been reported $[15,30]$.

4.2. Air Temperature Change and Urban Development. It has been confirmed that there is a large air temperature difference in urban and rural areas [4-7]. These air temperature differences result from the influence of the thermal emissivity properties of urban surfaces and the three-dimensional configuration and heat capacity of erected structures onto the air temperature patterns in an urban region $[7,15,31]$. Most of the world's cities thus show higher air temperatures in the urban core than in the surrounding rural areas $[4,5,7]$. For example in Beijing City, China, Kuang et al. [32] measured that the mean land surface temperature of urban impervious surfaces was about $6-12^{\circ} \mathrm{C}$ higher than that of the urban green space and that in built-up areas was on average $3-6^{\circ} \mathrm{C}$ higher than in rural areas. They showed the main reason is the higher ratio of sensible heat to net radiation (0.63) and lower ratio of the latent heat to net radiation (0.19) on the urban impervious surface as compared to the corresponding rates of 0.30 and 0.63 in green space and cropland. In this study, there is no obvious temporal trend in the air temperature before 1978, whereas, after that time, the temperature increased greatly, although it showed a slight declining trend in recent years. The large air temperature increase from 1978 to 2002 may be due to the increasing area of construction and the decrease in farmland [32]. Figure 13 shows the changes in the farmland and construction areas. It can be found that there was a rapid increase in construction areas and an abrupt decrease in farmland areas after 1978, which led to a change in the thermal balance and then resulted in the increase in the air temperature in Shenzhen city. 


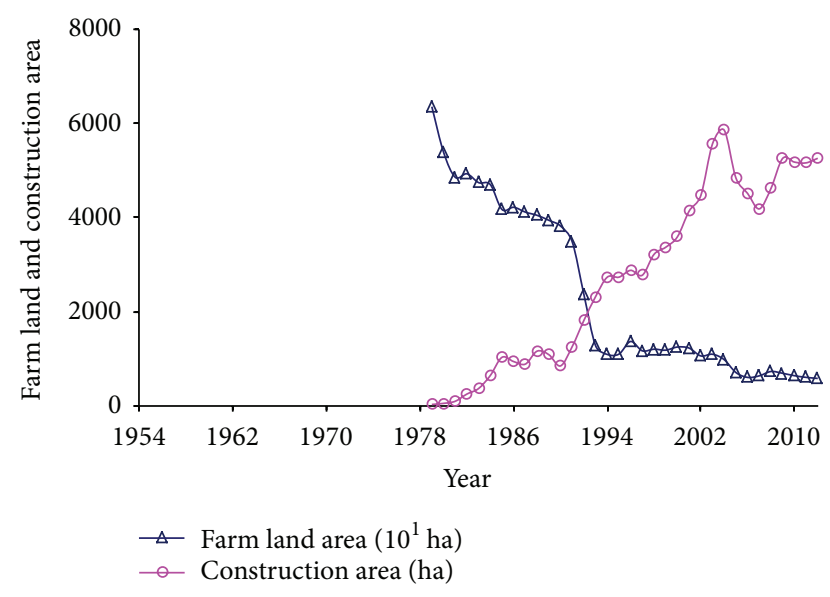

FIgURE 13: Temporal trend of the farmland area and the floor space of the buildings under construction.

4.3. Changes in the Relative Humidity and the Vapor Pressure Deficit due to Urban Development. The vapor pressure deficit was calculated by the air temperature and the relative humidity following the method of Allen et al. (1998) [12]. It is clearly shown in the calculation method that the vapor pressure deficit (VPD) increases with air temperature and decreases with relative humidity. In this study, both relative humidity and mean air temperature varied slightly during the period from 1954 to 1980 (Figures 5 and 6), which consequently resulted in a slight change in the vapor pressure deficit. After that period, the mean air temperature increased significantly, and the relative humidity was decreased remarkably. These trends resulted in an increase in the vapor pressure deficit (Figure 7).

The relative humidity is defined as the ratio of the water vapor density (mass per unit volume) to the saturation water vapor density, and it is also approximately the ratio of the actual to the saturation vapor pressure. A greater evaporative area may produce more water vapor for the atmosphere and then increase the water vapor density as well as the relative humidity at a given temperature. In the city study area, the farmland area decreased, whereas the construction area increased (Figure 13). These data indicate a decreasing trend in the evaporative area, which may result in a decrease in the water vapor density as well as the relative humidity [33]. Similarly, a decreasing trend of relative humidity and an increase in the vapor pressure deficit were observed in Beijing, Datong in Shanxi province, Zhang Jiakou in Hebei Province, and Bet Dagan in Israel $[15,34,35]$. In Beijing, it was shown that the VPD increased with air temperature and decreased with relative humidity from 1951 to 2010 [15]. Cohen et al. (2002) showed that the main factor responsible for the increased pan evaporation was the growth in the aerodynamic component of evaporation, which was due to increases in both the air VPD and the wind speed at Bet Dagan from 1964 to 1997 [35].

The vapor pressure deficit represents a gradient across which water vapor is removed from the evapotranspiring surface into the surrounding air [12]. A greater vapor pressure deficit generally causes a higher evaporative rate. Hence, the increasing vapor pressure deficit in the Shenzhen area will result in increasing plant evapotranspiration.

4.4. $E T_{0}$ Change and City Development. In the current study area, $\mathrm{ET}_{0}$ first decreased from 1950s to 1970s and then increased greatly in the 1980s. During the 1990s and 2000s it varied slightly, with a mean value of $1287 \mathrm{~mm}$. It was observed that, after the onset of urban development in 1978, the $\mathrm{ET}_{0}$ value increased and became higher than this for the period prior to the urban development. Figures 2, 5, 6, and 8 show that the mutation points for most climatic variables were observed near the onset year of urban development and sensitivity analysis shows that the higher $\mathrm{ET}_{0}$ during the period of 1992-2012 is mainly attributed to the relative humidity decrease and air temperature increase. Hence, it could be concluded that the quick development of Shenzhen city altered the climatic conditions and hence increased the local $\mathrm{ET}_{0}$. In other large cities, an increasing $\mathrm{ET}_{0}$ trend was also found in recent decades. For example, in Beijing City, the annual $\mathrm{ET}_{0}$ increased significantly from 1951 to 2010 and from the 1950s to 2000s, it increased from 1039 to $1148 \mathrm{~mm}$ [15]. The annual potential evapotranspiration (PET) displays a significant, upward trend from 1970 to 2006, and the trend varied from 1 to $4 \mathrm{~mm}$ per year in the Pyrénées-Orientales and Aude administrative departments, respectively, and the western part of the French Mediterranean area with an average increase in PET of between $34 \mathrm{~mm}$ and $150 \mathrm{~mm}$ in the last 36 years [36].

The increasing trend in $\mathrm{ET}_{0}$ that was observed in large cities is different than this that was found in the farmland. For example, in the Haihe River basin in northern China, decreasing trends were observed in 26 stations while 16 stations showed significant decreasing trends from 1950 to 2007 with rates from -2.0 to -3.7 mm year $^{-1}$ [34]. Similarly, a significant decreasing trend of $\mathrm{ET}_{0}$ with a rate of $-3 \mathrm{~mm}$ per year was found in the arid region of northwest China [37]. The difference trend in $\mathrm{ET}_{0}$ between the large cities and the farmland may be due to the variations in the energy balance and the evaporative potential. In the farmland areas, more than $60-80 \%$ of the net radiation is used for plant evapotranspiration $[33,38,39]$. This effect not only reduces the available heat for heating the air environment but also increases the water vapor in the near atmosphere. The latter effect may increase the relative humidity and reduce the vapor pressure deficit and lastly it may reduce the reference evapotranspiration. For urban conditions, the decrease in green land will decrease the energy consumption caused by crop evapotranspiration, increasing the available heat and decreasing the water vapor, which ultimately results in an increase in the evaporative potential.

It should be noted in Figure 9 that the $\mathrm{ET}_{0}$ values in 1997 and 2012 were much lower than those in the neighboring years. It is estimated that $\mathrm{ET}_{0}$ in 1997 and 2012 decreased by $-10.4 \%$ and $-13.0 \%$ compared to the mean value for the period from 1990 to 2012. The sensitive analysis method described in Section 3.3 was used to determine the effects of each variable on the $\mathrm{ET}_{0}$ changes in 1997 and 2012 compared to the mean value during the period of 1990-2012. The 
results showed that the changes in the relative humidity, air temperature, sunshine hours, and wind speed in 1997 resulted in changes in $\mathrm{ET}_{0}$ by $-7.2,-0.8,-2.0$, and $-0.5 \%$, respectively, and by $-12.6,-0.8,-0.6$, and $-4.2 \%$ in 2012 , respectively. It could be concluded that the increase in the relative humidity is the main factor for $\mathrm{ET}_{0}$ reduction, followed by the wind speed, air temperature, and sunshine hours in the two years.

Based on the mean values of the climatic variables averaged over the periods of 1954-1978 and 1992-2012, $\mathrm{ET}_{0}$ increased by $14.5 \%$ in the latter period. For the sensitivity analysis, changes in the relative humidity, air temperature, wind speed, and sunshine hours during 1992-2012 caused the variation of $\mathrm{ET}_{0}$ by $14.6,5.0,-1.3$, and $-3.8 \%$, respectively, compared to those for the period 1954-1978. The total amount of change in $\mathrm{ET}_{0}$ was $15.6 \%$, based on the sensitivity analysis. This value is similar to the rate of increase of $14.5 \%$ by comparison of the $\mathrm{ET}_{0}$ values between the two time periods. Liu et al. (2014) [15] calculated the $\mathrm{ET}_{0}$ change rates by directly comparing the mean values and summing each $\mathrm{ET}_{0}$ change rate caused by climatic variables using the same sensitive analysis method: the $\mathrm{ET}_{0}$ change rates were $10.7 \%$ and $10.5 \%$, respectively. Liu et al. (2009) [40] found that $\mathrm{ET}_{0}$ inside the screenhouse was reduced by $39 \%$ compared to that in the open field. By considering the effect of each climatic variable change to $\mathrm{ET}_{0}$ using the sensitivity analysis, the total $\mathrm{ET}_{0}$ change rate sums to $44 \%$, which is similar to the value of $39 \%$. Therefore, it could be concluded that the sensitivityanalysis method used in this study is reliable and easy to use, and hence it is recommended for the analysis of the effect of climate change on $\mathrm{ET}_{0}$.

\section{Conclusions}

(1) The development of Shenzhen city greatly affected the local climatic conditions. Before the onset of urban development, each climatic variable varied slightly, whereas, afterward, the air temperature increased significantly, and the sunshine hours and relative humidity decreased significantly. The mutation point for most climatic variables is observed at approximately 1978 , the onset year for urban development.

(2) $\mathrm{ET}_{0}$ first decreased from 1954 to 1978 and then increased quickly and reached a maximal value of $1373 \mathrm{~mm}$ during the period from 1992 to 2012. The mean $\mathrm{ET}_{0}$ value for the period from 1954 to 1978 was $1110 \mathrm{~mm}$ and increased to $1284 \mathrm{~mm}$ during the period from 1992 to 2012, indicating an increasing trend of the evaporative demand.

(3) Sensitivity analysis showed that $\mathrm{ET}_{0}$ is most sensitive to relative humidity, followed by air temperature, sunshine hours, and wind speed.

\section{Conflict of Interests}

The authors declare that there is no conflict of interests regarding the publication of this paper.

\section{Acknowledgments}

This paper is partially supported by the National Science Foundation of China (Grant nos. 51179005, 51479004). The authors greatly acknowledge the comments from the editor and the two anonymous reviewers.

\section{References}

[1] IPCC, Climate Change 2014: Synthesis Report. An Assessment of Intergovernmental Panel on Climate Change, IPCC, Geneva, Switzerland, 2014, http://ipcc.ch/index.html.

[2] J. D. Haskett, Y. A. Pachepsky, and B. Acock, "Effect of climate and atmospheric change on soybean water stress: a study of Iowa," Ecological Modelling, vol. 135, no. 2-3, pp. 265-277, 2000.

[3] T. G. Huntington, "Evidence for intensification of the global water cycle: review and synthesis," Journal of Hydrology, vol. 319, no. 1-4, pp. 83-95, 2006.

[4] B. C. Bates, Z. W. Kundzewicz, S. Wu, and J. Palutikof, "Climate change and water," Technical Paper of the Intergovernmental Panel on Climate Change, IPCC Secretariat, Geneva, Switzerland, 2008.

[5] C. M. Philandras, D. A. Metaxas, and P. T. Nastos, "Climate variability and urbanization in Athens," Theoretical and Applied Climatology, vol. 63, no. 1-2, pp. 65-72, 1999.

[6] R. L. Wilby, "Past and projected trends in London's urban heat island," Weather, vol. 58, no. 7, pp. 251-260, 2003.

[7] N. Schwarz, U. Schlink, U. Franck, and K. Großmann, "Relationship of land surface and air temperatures and its implications for quantifying urban heat island indicators-an application for the city of Leipzig (Germany)," Ecological Indicators, vol. 18, pp. 693-704, 2012.

[8] H. Wang, L. Fu, X. Lin, Y. Zhou, and J. C. Chen, "A bottomup methodology to estimate vehicle emissions for the Beijing urban area," Science of the Total Environment, vol. 407, no. 6, pp. 1947-1953, 2009.

[9] DESE (Department of Environmental Science and Engineering/Tsinghua University), Mobile Source Database, Emission Inventory and Treatment Proposal for Beijing, Tsinghua University, Beijing, China, 2005.

[10] H. Kan, S. J. London, G. Chen et al., "Differentiating the effects of fine and coarse particles on daily mortality in Shanghai, China," Environment International, vol. 33, no. 3, pp. 376-384, 2007.

[11] A. Aziz and I. U. Bajwa, "Erroneous mass transit system and its tended relationship with motor vehicular air pollution (An integrated approach for reduction of urban air pollution in Lahore)," Environmental Monitoring and Assessment, vol. 137, no. 1-3, pp. 25-33, 2008.

[12] R. G. Allen, L. S. Perreira, D. Raes, and M. Smith, Crop Evapotranspiration: Guidelines for Computing Crop Water Requirements, FAO Irrigation and Drainage Paper no. 56, FAO, Rome, Italy, 1998.

[13] K. H. Hamed, "Trend detection in hydrologic data: the MannKendall trend test under the scaling hypothesis," Journal of Hydrology, vol. 349, no. 3-4, pp. 350-363, 2008.

[14] L. Q. Liang, L. J. Li, and Q. Liu, “Temporal variation of reference evapotranspiration during 1961-2005 in the Taoer River basin of Northeast China," Agricultural and Forest Meteorology, vol. 150, no. 2, pp. 298-306, 2010. 
[15] H. Liu, Y. Li, T. Josef, R. H. Zhang, and G. H. Huang, "Quantitative estimation of climate change effects on potential evapotranspiration in Beijing during 1951-2010," Journal of Geographical Sciences, vol. 24, no. 1, pp. 93-112, 2014.

[16] M. G. Kendall and A. Stuart, The Advanced Theory of Statistics, Griffin, London, UK, 1973.

[17] Q.-Y. Tang and C.-X. Zhang, "Data Processing System (DPS) software with experimental design, statistical analysis and data mining developed for use in entomological research," Insect Science, vol. 20, no. 2, pp. 254-260, 2013.

[18] M. Möller, J. Tanny, Y. Li, and S. Cohen, "Measuring and predicting evapotranspiration in an insect-proof screenhouse," Agricultural and Forest Meteorology, vol. 127, no. 1-2, pp. 35-51, 2004.

[19] G. Kitsara, G. Papaioannou, A. Papathanasiou, and A. Retalis, "Dimming/brightening in athens: trends in sunshine duration, cloud cover and reference evapotranspiration," Water Resources Management, vol. 27, no. 6, pp. 1623-1633, 2013.

[20] Y. Wang, Y. Yang, S. Han, Q. X. Wang, and G. H. Zhang, "Sunshine dimming and brightening in Chinese cities (19552011) was driven by air pollution rather than clouds," Climate Research, vol. 56, no. 1, pp. 11-20, 2013.

[21] G. Stanhill and S. Cohen, "Global dimming: a review of the evidence for a widespread and significant reduction in global radiation with discussion of its probable causes and possible agricultural consequences," Agricultural and Forest Meteorology, vol. 107, no. 4, pp. 255-278, 2001.

[22] Q. Liu and Z. Yang, "Quantitative estimation of the impact of climate change on actual evapotranspiration in the Yellow River Basin, China," Journal of Hydrology, vol. 395, no. 3-4, pp. 226234, 2010 .

[23] D. I. Stern, "Reversal of the trend in global anthropogenic sulfur emissions," Global Environmental Change, vol. 16, no. 2, pp. 207220, 2006.

[24] I. Koren, J. V. Martins, L. A. Remer, and H. Afargan, "Smoke invigoration versus inhibition of clouds over the Amazon," Science, vol. 321, no. 5891, pp. 946-949, 2008.

[25] D. Rosenfeld, Y. J. Kaufman, and I. Koren, "Switching cloud cover and dynamical regimes from open to closed Benard cells in response to the suppression of precipitation by aerosols," Atmospheric Chemistry and Physics, vol. 6, no. 9, pp. 2503-2511, 2006.

[26] C. Ruckstuhl, R. Philipona, K. Behrens et al., "Aerosol and cloud effects on solar brightening and the recent rapid warming," Geophysical Research Letters, vol. 35, no. 12, Article ID L12708, 2008.

[27] D. G. Streets, Y. Fang, C. Mian et al., "Anthropogenic and natural contributions to regional trends in aerosol optical depth, 19802006," Journal of Geophysical Research: Atmospheres, vol. 114, no. 10, Article ID D00D18, 2009.

[28] V. Ramanathan, P. J. Crutzen, J. T. Kiehl, and D. Rosenfeld, "Atmosphere-aerosols, climate, and the hydrological cycle," Science, vol. 294, no. 5549, pp. 2119-2124, 2001.

[29] M. Wild, "Enlightening global dimming and brightening," Bulletin of the American Meteorological Society, vol. 93, no. 1, pp. 27-37, 2012.

[30] G. D. Liu, Y. Li, H. J. Liu, and J. Xiao, "Changing trend of reference crop evapotranspiration and its dominated meteorological variables in Shanxi province in the past 55 years," Journal of Irrigation and Drainage, vol. 31, no. 4, pp. 26-30, 2012.
[31] C.-S. Rim, "The effects of urbanization, geographical and topographical conditions on reference evapotranspiration," Climatic Change, vol. 97, no. 3, pp. 483-514, 2009.

[32] W. Kuang, Y. Liu, Y. Dou et al., "What are hot and what are not in an urban landscape: quantifying and explaining the land surface temperature pattern in Beijing, China," Landscape Ecology, 2014.

[33] Z. Qin, Q. Yu, S. Xu et al., "Water, heat fluxes and water use efficiency measurement and modeling above a farmland in the North China Plain," Science in China D: Earth Sciences, vol. 48, no. 1, pp. 207-217, 2005.

[34] B. Tang, L. Tong, S. Z. Kang, and L. Zhang, "Impacts of climate variability on reference evapotranspiration over 58 years in the Haihe river basin of north China," Agricultural Water Management, vol. 98, no. 10, pp. 1660-1670, 2011.

[35] S. Cohen, A. Ianetz, and G. Stanhill, "Evaporative climate changes at Bet Dagan, Israel, 1964-1998," Agricultural and Forest Meteorology, vol. 111, no. 2, pp. 83-91, 2002.

[36] K. Chaouche, L. Neppel, C. Dieulin et al., "Analyses of precipitation, temperature and evapotranspiration in a French Mediterranean region in the context of climate change," Comptes Rendus Geoscience, vol. 342, no. 3, pp. 234-243, 2010.

[37] Z. Huo, X. Dai, S. Feng, S. Kang, and G. Huang, "Effect of climate change on reference evapotranspiration and aridity index in arid region of China," Journal of Hydrology, vol. 492, pp. 2434, 2013.

[38] G. Peng, X. Cai, H. Zhang, A. Li, F. Hu, and M. Y. Leclerc, "Heat flux apportionment to heterogeneous surfaces using flux footprint analysis," Advances in Atmospheric Sciences, vol. 25, no. 1, pp. 107-116, 2008.

[39] Y. Q. Zhang, Y. J. Shen, C. M. Liu et al., "Measurement and analysis of water, heat and $\mathrm{CO}_{2}$ flux from a farmland in the North China plain," Acta Geographica Sinica, vol. 57, no. 3, pp. 333-342, 2002 (Chinese).

[40] H.-J. Liu, G.-H. Huang, S. Cohen, and J. Tanny, "Change in crop evapotranspiration and associated influencing factors under screenhouse conditions," Chinese Journal of Eco-Agriculture, vol. 17, no. 3, pp. 484-488, 2009 (Chinese). 

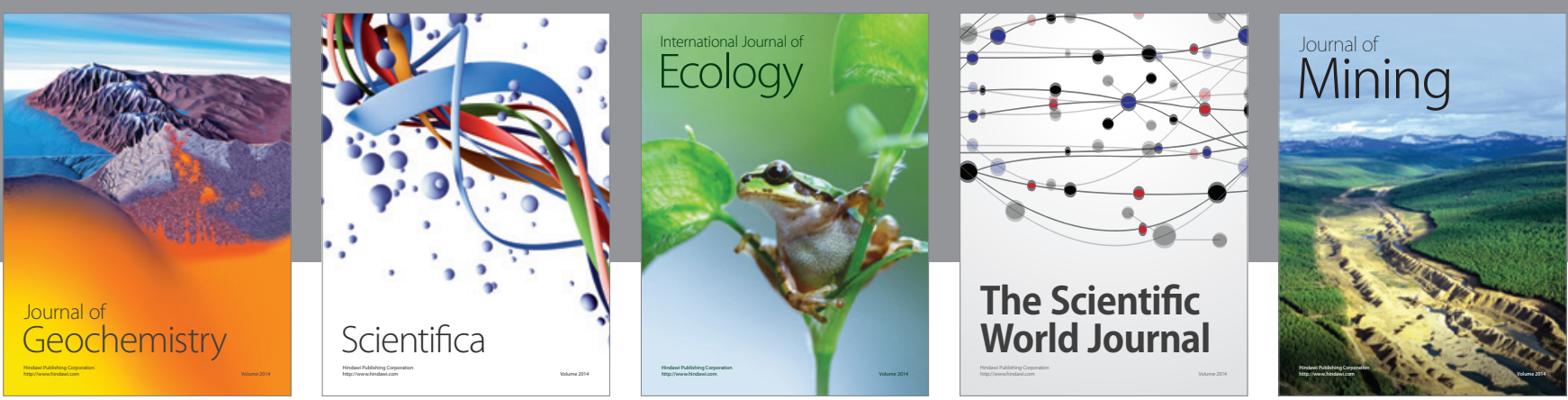

The Scientific World Journal
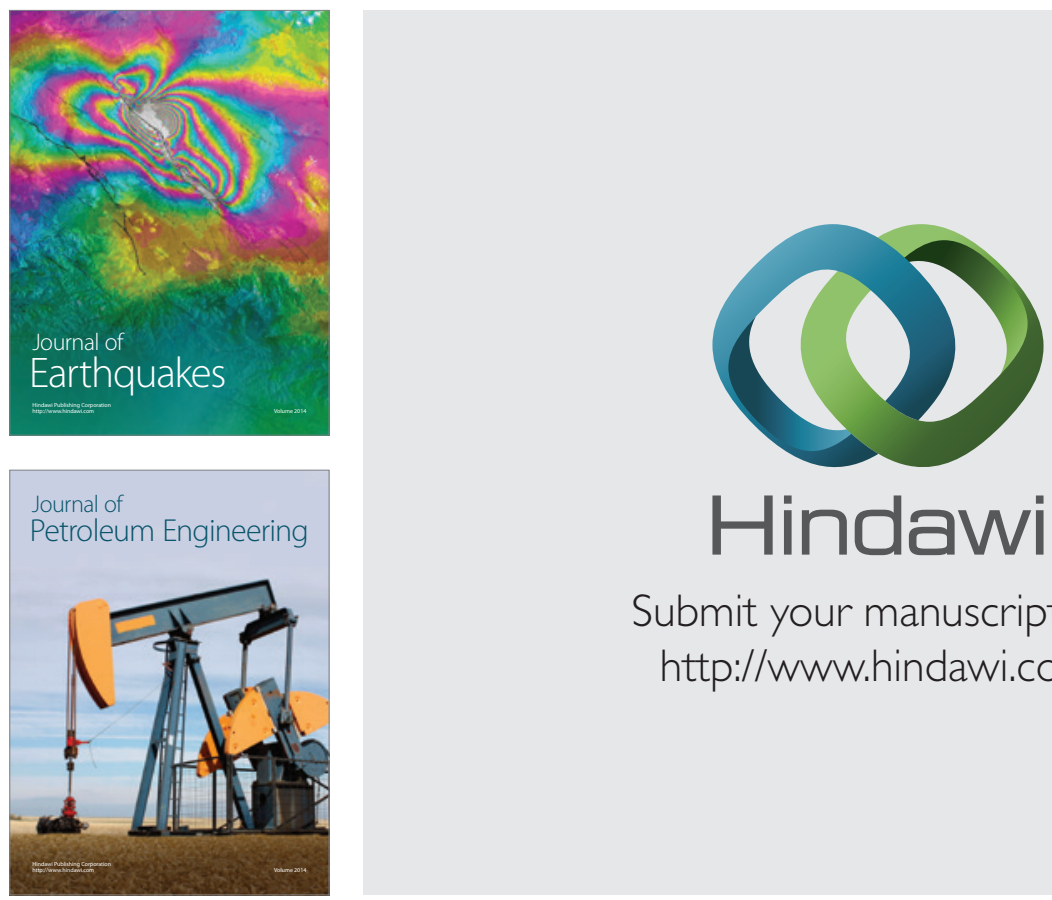

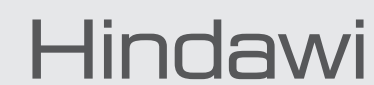

Submit your manuscripts at

http://www.hindawi.com
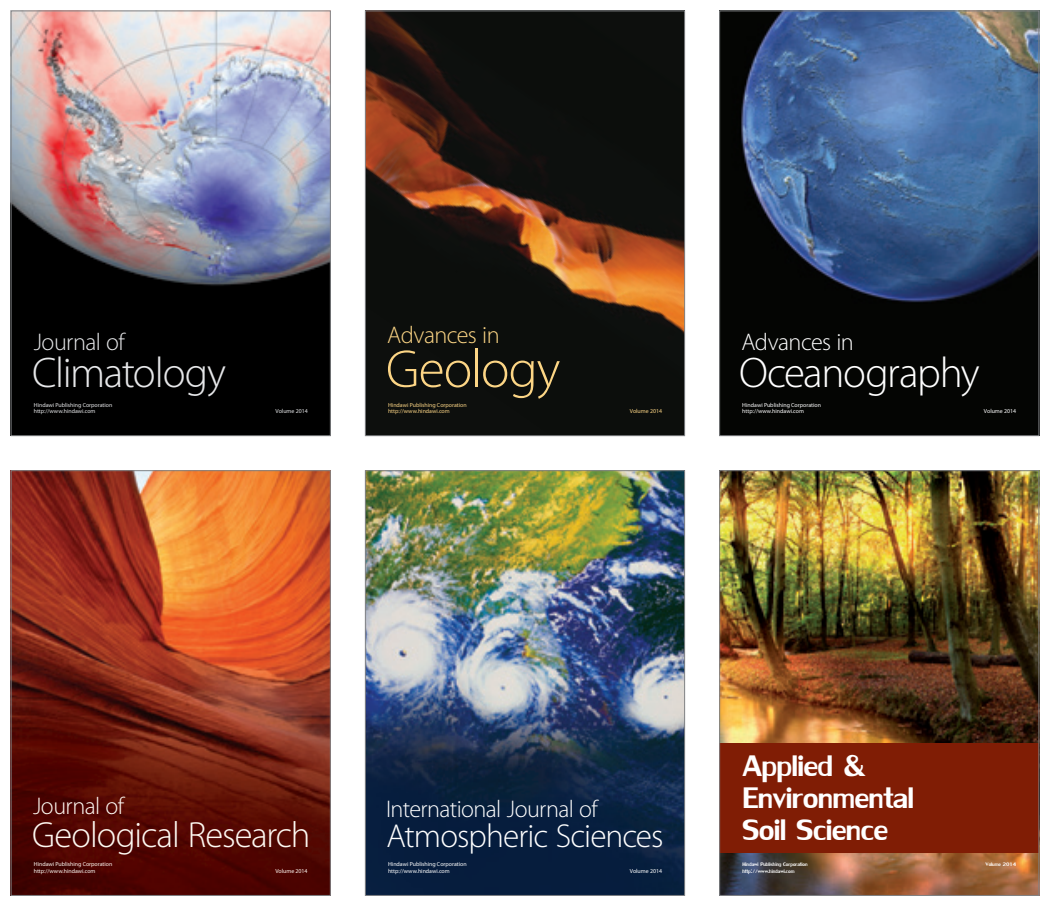
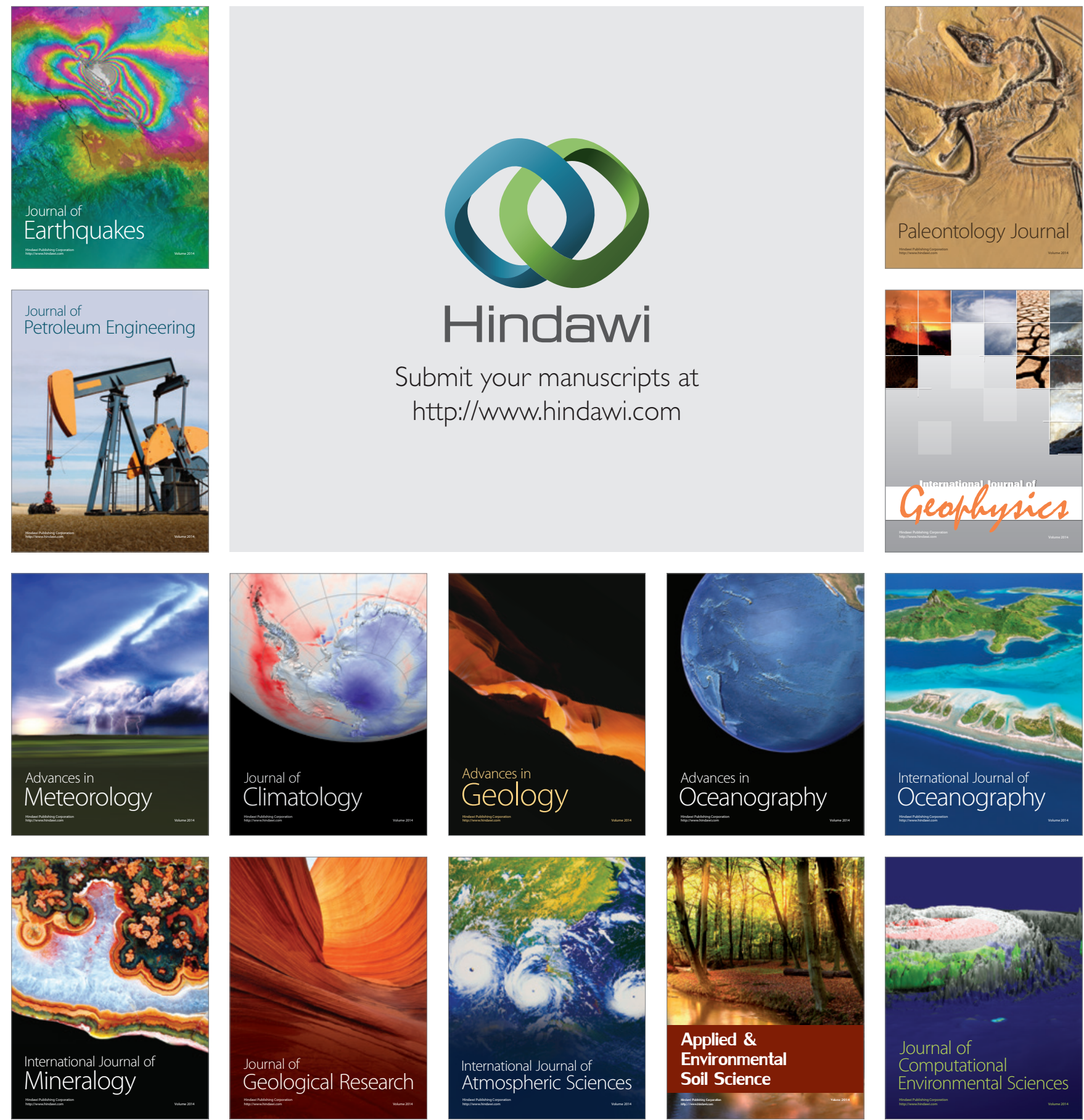